\title{
Can Simple Strategies Beat S\&P 500?
}

\author{
Pawan K. Madhogarhia \\ York College of Pennsylvania
}

Buy and hold strategies typically outperform active management of portfolios. Few active strategies though outperform passive strategies. This study is an attempt to back-test some simple active strategies that most investors can replicate with little effort. Criteria for these strategies include size and/or value strategies applied within the $S \& P 500$ index. These strategies consistently outperform the $S \& P 500$ index total return over a long period. Size, value, and a combination of size, and value generated positive excess returns. This study corroborates the emergence of smart beta strategies and factor-based investing that is gaining traction in financial markets.

Keywords: S\&P 500, Index, Value, Growth, Smart Beta, Factor-Based Investing, Outperformance, Backtesting

\section{INTRODUCTION}

Value stocks typically outperform growth stocks over long periods of time (Fama and French, 1998). Value may be defined as those stocks that meet certain criteria such as those that have lower P/E, P/B, $\mathrm{P} / \mathrm{CF}$ or higher dividend yield than the averages for a group of stocks. Fama \& French, and Chen \& Zhang, provide evidence that high book-to-market (B/M) firms have persistently lower earnings, higher financial leverage, and higher earnings uncertainty (Fama \& French,1995 and Chen \& Zhang, 1998). Lakonishok, Shleifer and Vishny argue that investor expectations are based on the extrapolation of recent past performance (Lakonishok, et. al., 1994). Therefore, investors with naïvely optimistic expectations about the prospects of glamour stocks tend to get overly excited about stocks that have done well in the past and they drive the prices of these stocks up, so that these glamour stocks become overpriced. When these overly optimistic expectations are not met, these stocks suffer significant losses. DeBondt and Thaler document that investors tend to overreact to recent stock market events (DeBondt et. al., 1987). When EPS expectations are not met, it adversely affects the market price of growth stocks more than value stocks. They argue that any mispricing is likely to be most pronounced in firms with a high degree of information asymmetry and where rational arbitrage is less likely to be effective. There is evidence that this behavior may be explained by disproportionately large and asymmetric responses to negative earnings surprises for growth stocks (Skinner and Sloan, 1999). Madhogarhia, Sutton and Kohers contend that growth firms have more incentives to "manage their earnings" and they provide evidence that they do so more aggressively compared to value firms (Madhogarhia et al., 2009).

Banz provide evidence that on average, smaller firms have higher risk adjusted returns than larger firms (Banz, 1981). It is likely that size could be simply a proxy for factors correlated with size or it could 
be a result of law of large numbers. It is relatively more difficult for larger firms to grow at the same rate as the smaller ones. Smaller firms could be considered relatively more risky than larger firms.

Bauman, Conover and Miller find that value stocks outperform growth stocks in all firm capitalization categories except the smallest size category (Bauman et. al., 1998). If change is a given, it implies smaller companies are expected to displace old leaders. A basket of smaller companies, though riskier in nature, tends to grow much faster than a basket of large companies. In this study, only large cap stocks are considered and hence smallest S\&P 500 value stocks are expected to outperform the index.

Savor and Cavazos find that short sellers cover their positions after suffering losses and increase positions after experiencing gains (Savor et. al., 2011). This momentum effect may make value stocks even more deeply valued as short sellers increase their positions after experiencing gains in these distressed stocks. On the other hand, they may cover their positions after they suffer losses in growth stocks that continue to go higher and these growth stocks may continue to glide higher. Value stocks can become even more valuable on pessimistic expectations and growth stocks can become overvalued on overly optimistic expectations. Stocks that have a high short interest may perform better than those with low short interest when any good news relating to high short interest stocks creates a short squeeze.

Daniel and others find evidence that an average mutual fund does outperform simple mechanical rules based on characteristics such as market capitalization, book to market value of equity and momentum (Daniel et. al., 1997). However, after accounting for fees the outperformance is approximately equal to management fees, implying that the managers outperform just enough to earn back their fees. Pablo and Pablo have shown in a working paper that it is relatively easy to beat S\&P 500 index by following simple mechanical rules (Pablo et. al., 2018). Jegadeesh and Titman find evidence that momentum strategies that buy winners with high returns over the previous 3 to 12 months and sell losers with poor returns over the same period generate significant positive returns of about one percent per month (Jegadeesh et. al., 1993). This momentum effect would make value stocks even more deeply valued over the short term. According to Poterba and Summers stock returns are positively serially correlated over short time horizons and negatively auto correlated over longer time horizons (Poterba and Summers, 1988). "If divergence between market values and intrinsic fundamental values exist over short periods of time then beyond some limit speculative forces may eliminate such divergence and hence asset values will exhibit mean reversion" (Madhogarhia and Lam, 2015). Therefore, we should expect value stocks to become more deeply undervalued over short time period and significantly outperform over the longer term. Plyakha, Uppal and Vilkov find evidence that equal-weighted portfolios outperform the value- and price-weighted portfolios on a total mean return basis and Sharpe ratio (Plyakha et. al., 2012). They also find that an equal weighted portfolio has greater portfolio risk. In an equally-weighted portfolio of large cap stocks, smaller market cap stocks are over-weighted relative to a market cap weighted index such as S\&P 500 index in which larger market cap stocks are over-weighted. Higher risk could be attributed to small cap bias as equal-weighted portfolios have inherently higher allocations to smaller cap stocks included in the portfolio. It is becoming increasingly popular that market capitalization weighted indexation is inefficient. Haugen and Baker show that market cap weighted stock portfolios are inefficient (Haugen and Baker, 1991). Equal weighting and fundamental factor- based indexation is becoming more popular. We also know that market cap weighted indices underperform equally weighted indices because of concentration of high market cap stocks in the market cap weighted indices. In contrast, equally weighted indices are concentrated in small cap stocks. Small cap stocks have generated better returns than large cap stocks over long time in 12 out of 13 major international markets (Fama and French, 1998).

Smart beta strategies can add value by strategically choosing, weighting and rebalancing based on objective factors. Factors can include volatility, momentum, size, value and quality. Systematic rebalancing could be built into the ETF technology itself and smart beta can expand investors' options based on each investor's preferences and time horizon. Kahn and Lemmon contend that smart beta products provide an important component of active management through simple and transparent rulesbased strategy in creating portfolios at lower cost (Kahn et. al., 2016). Asset managers need to distinguish between mix of smart beta, pure alpha in their products and their competitive advantages in delivering these important components. The approach taken in this paper is similar in many respects to smart beta 
strategies and the factors employed in the strategy discussed in this paper are based primarily on size and value with annual rebalancing.

This study explores simple strategies over different periods using a combination of the abovementioned criteria to test whether these strategies can beat a buy-and-hold strategy for the S\&P 500 index. The next section provides data description followed by a discussion on methodology. The next section provides reflections on results. Finally, the last section sheds light on conclusions from this paper.

\section{DATA}

Bloomberg terminal was used to screen for stocks based on different criteria such as size, $\mathrm{P} / \mathrm{E}, \mathrm{P} / \mathrm{B}$, PEG ratio, short interest ratio etc. Different periods and a combination of different criteria were used to screen and back-test different strategies.

\section{METHODOLOGY}

Using Bloomberg terminal stocks were screened and ranked based on size. The lowest 20 market cap stocks within the S\&P 500 index were chosen to form a portfolio and the portfolio was rebalanced annually as of the last trading day of the year. Once 20 stocks with lowest market cap were identified, they were equally weighted to form the portfolio. This portfolio is designated as bottom 20 portfolio. This process was repeated over different time periods ranging from 5 to 25 years. The study could not go beyond 25 years as Bloomberg did not have data and back-testing available before 12/31/1992. The performance of these different portfolios was back-tested against the S\&P 500 index. Results are available in Table I. As a robustness check more portfolios were created using 40, 60 and 80 smallest market capitalization stocks within the index and these were designated as bottom 40,60 and 80 portfolios.

Again, using the Bloomberg terminal stocks were screened using a combination of the following criteria:

1. Constituents are part of the S\&P 500 index

2. $\mathrm{P} / \mathrm{E}$ ratio lower than the average $\mathrm{P} / \mathrm{E}$ ratio for the index

3. $\mathrm{P} / \mathrm{B}$ ratio lower than the average $\mathrm{P} / \mathrm{B}$ ratio for the index

4. Short interest ratio lower than the average short interest ratio for the index

5. Market capitalization lower than the average marketcapitalization for the index

6. Dividend yield higher than the average dividend yield for the index

7. Latest filing return on invested capital greater than the latest filing average return on invested capital for the index.

This portfolio was also rebalanced annually, and equally-weighted portfolios were created over different periods of time. These portfolios are designated as value portfolios. These portfolios were backtested against the S\&P 500 index. Results are summarized in Table II.

Screening for value and size is based on the above value criteria however, screening for size is based on bottom $30 \%, 40 \%$ and $50 \%$ of the market capitalizations of the constituents of the index. Unlike the size only criteria where bottom 20, 40, 60 or 80 market capitalization stocks were chosen, higher percentages were chosen to ensure that there were reasonable number of stocks in the portfolio and different percentages were chosen for robustness check. This portfolio was also rebalanced annually, and equally-weighted portfolios were created over different periods of time. These portfolios are designated as value_size portfolios. Again, these portfolios were back-tested against the S\&P 500 index. Results are summarized in Table II.

\section{RESULTS}

It is clear from Table I that the bottom 20 market capitalization portfolios within the S\&P 500 index generate higher returns than the index itself on a cumulative basis over most periods ranging from 5 to 25 
years. Robustness checks were performed using bottom 40,60 and 80 market capitalization stocks within the index. Most of the small cap portfolios outperformed the index. The best cumulative returns were generated by the 80 lowest market capitalization stocks for all 5 periods - 5, 10, 15, 20 and 25-year periods. The best annualized returns were generated for the 15-year period from 2003 through 2017 for all four size-based portfolios.

Value portfolios outperformed most size based portfolios as well as the index for almost all periods both on a cumulative and annualized return basis. Small cap value portfolios created using a combination of size, value and short interest outperformed the index by a wide margin over different periods both on a cumulative and annualized return basis, as depicted in Table II. Interestingly, the combination strategy also outperformed the size strategy by wide margins over different periods both on a cumulative and annualized return basis. Specifically, the combination strategy with lowest 30\% market cap stocks yielded a cumulative return of $2848.88 \%$ over a 15 -year period (See Table II) relative to the maximum return of $704.22 \%$ for the bottom 80 stock portfolio based on market capitalization for the same period (See Table I).

It is clear from the Bloomberg charts that the screens outperformed the index in all cases after 2009. Prior to 2009 the results were mixed. This might suggest an important outcome of this study that the results of this study could be economic cycle dependent as 2009 marked the end of the Great Recession. However, the bottom 20 stocks in the S\&P 500 index closely matched the performance of the index until 2009 and consistently outperformed the index thereafter (See Figure 1).

The bottom 40 to 80 stock portfolios outperformed the index for all periods analyzed ranging from 10 to 25 years. All value and size combination portfolios outperformed the index for all periods ranging from 5 to 25 -year periods analyzed except for a single value portfolio which was screened by ranking bottom $50 \%$ market cap of the index (See Table 2).

Highest returns were generated for bottom 80 -stock portfolios for all periods except the 20-year period. Most returns were generated for 15-year periods for all size portfolios. Returns increased substantially when the number of small stocks increased from bottom 20 to bottom 40. However, annualized returns increased marginally when small stocks increased from bottom 40 to 60 and 80 stock portfolios (See Table 1).

Best returns were generated for value_size portfolios for the bottom $30 \%$ size portfolios for all periods except the 5-year period. Highest cumulative return was generated for this portfolio over a 15 year period. Highest annualized return was generated by this portfolio over a 10-year period. Maximum annualized returns were generated over 10 or 15-year periods for most value_size portfolios (See Table 2).

\section{CONCLUSIONS}

This study corroborates size and value factors' contributions to returns when applied to different subsets of S\&P 500 index (Fama and French, 1998). Small size portfolios carved out of the index typically out- performed the index and small value portfolios out-performed small portfolios for most comparable periods analyzed. Based on size, the bottom $30 \%$ value portfolios outperformed the bottom $40 \%$ or $50 \%$ value portfolios for all periods except the 5 -year period. Bottom 60 -size portfolio generated an excess annualized return of $8.54 \%$ over a 15 -year period (See Table 1) and the bottom $30 \%$ value_size portfolio generated excess annualized return of $20.4 \%$ over the same period (See Table 2). Combination strategy generated a cumulative return of $2849 \%$ relative to the highest cumulative return of $704 \%$ for the size factor and $1019 \%$ for the value factor over this 15-year period. The S\&P 500 index generated cumulative returns of $313.15 \%$ over the same period (See Tables 1 and 2).

Additionally, it appears that some factors become more important post major recessions and value may outperform growth or blend strategies. Over the past several years, objective factor-based investing has become popular as smart beta strategy and this study may partially explain the success of these strategies. Factor based investing models typically outperform an index if factors are chosen appropriately. 
TABLE 1

RETURNS FOR SIZE PORTFOLIOS AND THE INDEX

\begin{tabular}{|l|l|l|l|l|l|l|}
\hline Period & Years & $\begin{array}{l}\text { \% Return } \\
\text { Portfolio_20 } \\
\text { stocks }\end{array}$ & $\begin{array}{l}\text { \% Return } \\
\text { Portfolio_40 } \\
\text { stocks }\end{array}$ & $\begin{array}{l}\text { \% Return } \\
\text { Portfolio_60 } \\
\text { Stocks }\end{array}$ & $\begin{array}{l}\text { \% Return } \\
\text { Portfolio_80 } \\
\text { Stocks }\end{array}$ & $\begin{array}{l}\text { \% } \\
\text { Return } \\
\text { S\&P 500 } \\
\text { Index }\end{array}$ \\
\hline $2013-2017$ & 5 & $\begin{array}{l}60.85 \\
(12.40)\end{array}$ & $\begin{array}{l}80.82 \\
(14.28)\end{array}$ & $\begin{array}{l}94.51 \\
(15.73)\end{array}$ & $\begin{array}{l}113.84 \\
(17.81)\end{array}$ & $\begin{array}{l}108.06 \\
(15.79)\end{array}$ \\
\hline $2008-2017$ & 10 & 112.41 & 203.54 & 230.84 & 250.71 & 125.86 \\
& $(14.49)$ & $(16.97)$ & $(17.36)$ & $(17.58)$ & $(8.49)$ \\
\hline $2003-2017$ & 15 & 440.49 & 623.54 & 678.52 & 704.22 & 313.15 \\
& $(17.58)$ & $(18.42)$ & $(18.46)$ & $(18.34)$ & $(9.92)$ \\
\hline $1998-2017$ & 20 & 808.00 & 672.48 & 862.63 & 952.83 & 301.08 \\
$(17.07)$ & $(14.61)$ & $(15.42)$ & $(15.63)$ & $(7.19)$ \\
\hline $1993-2017$ & 25 & 808.00 & 1385.67 & 2215.92 & 2608.82 & 907.98 \\
& & $(13.44)$ & $(15.63)$ & $(16.40)$ & $(16.83)$ & $(9.68)$ \\
\hline
\end{tabular}

This table shows cumulative returns for portfolios ranked based on size. Returns in parentheses represent annual mean returns.

TABLE 2

RETURNS FOR VALUE, COMBINATION PORTFOLIOS AND THE INDEX

\begin{tabular}{|c|c|c|c|c|c|c|}
\hline Period & Years & $\begin{array}{l}\text { \% Return } \\
\text { Value } \\
\text { Portfolio }\end{array}$ & $\begin{array}{l}\text { \% Return } \\
\text { Value_Size_ } \\
30 \% \\
\text { Portfolio }\end{array}$ & $\begin{array}{l}\text { \% Return } \\
\text { Value_Size_ } \\
40 \% \\
\text { Portfolio }\end{array}$ & $\begin{array}{l}\text { \% Return } \\
\text { Value_Size_ } \\
50 \% \\
\text { Portfolio }\end{array}$ & $\begin{array}{l}\text { \% Return } \\
\text { S\&P } 500 \\
\text { Index }\end{array}$ \\
\hline 2013-2017 & 5 & $\begin{array}{l}167.75 \\
(23.06)\end{array}$ & $\begin{array}{l}114.43 \\
(18.74)\end{array}$ & $\begin{array}{l}133.73 \\
(20.39)\end{array}$ & $\begin{array}{l}95.89 \\
(15.91)\end{array}$ & $\begin{array}{l}108.06 \\
(15.79)\end{array}$ \\
\hline $2008-2017$ & 10 & $\begin{array}{l}508.31 \\
(23.31)\end{array}$ & $\begin{array}{l}1080.66 \\
(34.64)\end{array}$ & $\begin{array}{l}915.60 \\
(31.27)\end{array}$ & $\begin{array}{l}526.94 \\
(23.87)\end{array}$ & $\begin{array}{l}125.86 \\
(8.49)\end{array}$ \\
\hline 2003-2017 & 15 & $\begin{array}{l}1018.85 \\
(20.20)\end{array}$ & $\begin{array}{l}2848.88 \\
30.32)\end{array}$ & $\begin{array}{l}2163.80 \\
(27.18)\end{array}$ & $\begin{array}{l}1340.18 \\
(22.48)\end{array}$ & $\begin{array}{l}313.15 \\
(9.92)\end{array}$ \\
\hline $1998-2017$ & 20 & $\begin{array}{l}1363.38 \\
(17.03)\end{array}$ & $\begin{array}{l}2066.63 \\
(21.37)\end{array}$ & $\begin{array}{l}1481.67 \\
(18.81)\end{array}$ & $\begin{array}{l}1288.79 \\
(17.04)\end{array}$ & $\begin{array}{l}301.08 \\
(7.19)\end{array}$ \\
\hline $1993-2017$ & 25 & $\begin{array}{l}2435.01 \\
(16.16)\end{array}$ & $\begin{array}{l}2066.15 \\
(17.29)\end{array}$ & $\begin{array}{l}1632.65 \\
(15.51)\end{array}$ & $\begin{array}{l}1972.34 \\
(15.60)\end{array}$ & $\begin{array}{l}907.98 \\
(9.68)\end{array}$ \\
\hline
\end{tabular}

This table shows cumulative returns for Value portfolios screened based on 6 criteria mentioned under methodology. The Value_Size portfolios represent the same value criteria, however, screening for size is based on bottom $30 \%$, $40 \%$ and $50 \%$ of the market capitalization of constituents of the index. Returns in parentheses represent annual mean returns. 
FIGURE 1

20 YEAR RETURNS FOR 20 SMALLEST STOCKS

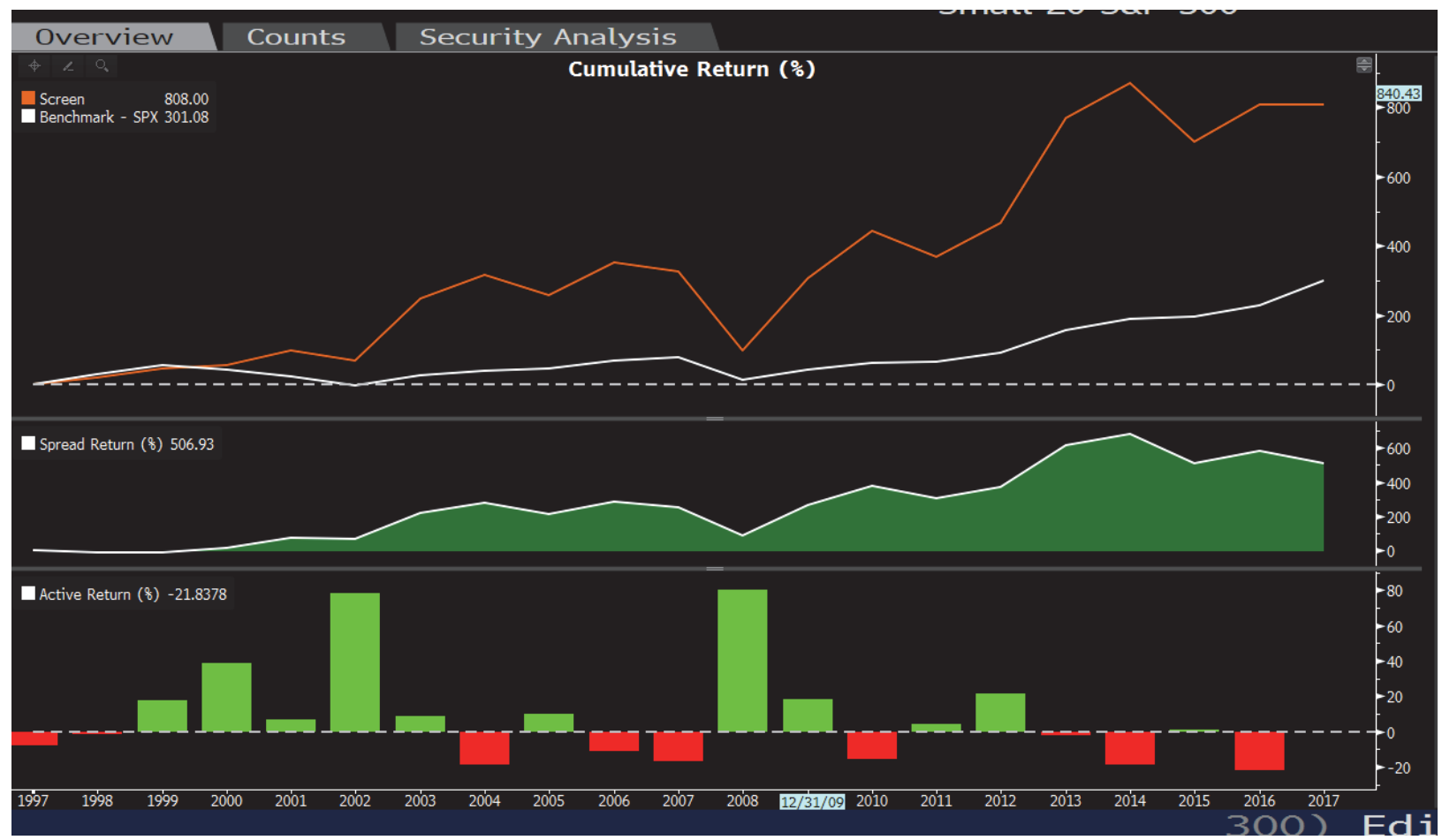

FIGURE 2

25 YEAR RETURNS FOR 20 SMALLEST STOCKS



140 Journal of Accounting and Finance Vol. 19(6 2019 


\section{FIGURE 3}

20 YEAR RETURNS FOR VALUE \& SIZE COMBINATION

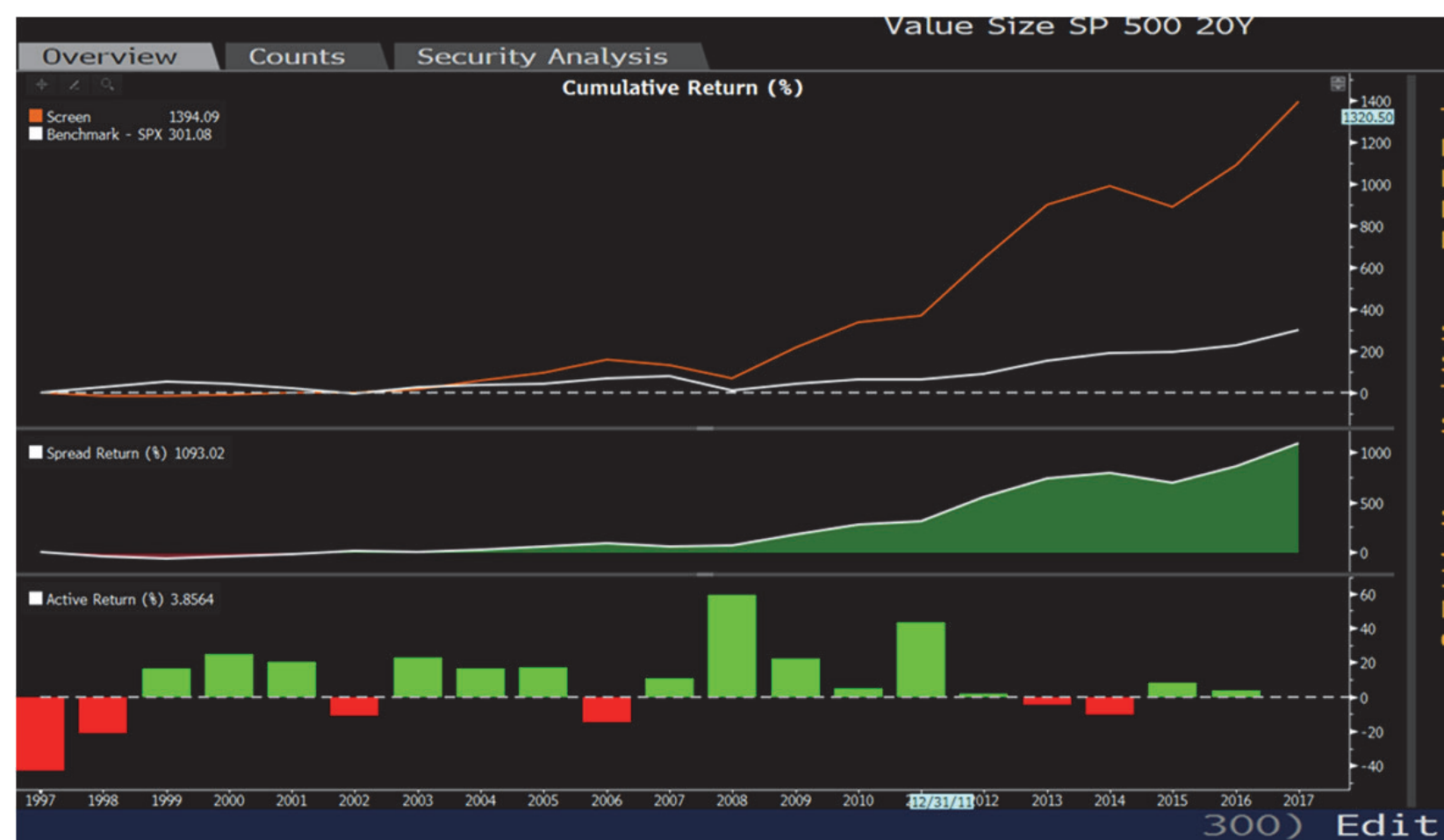

FIGURE 4

25 YEAR RETURNS FOR VALUE \& SIZE COMBINATION

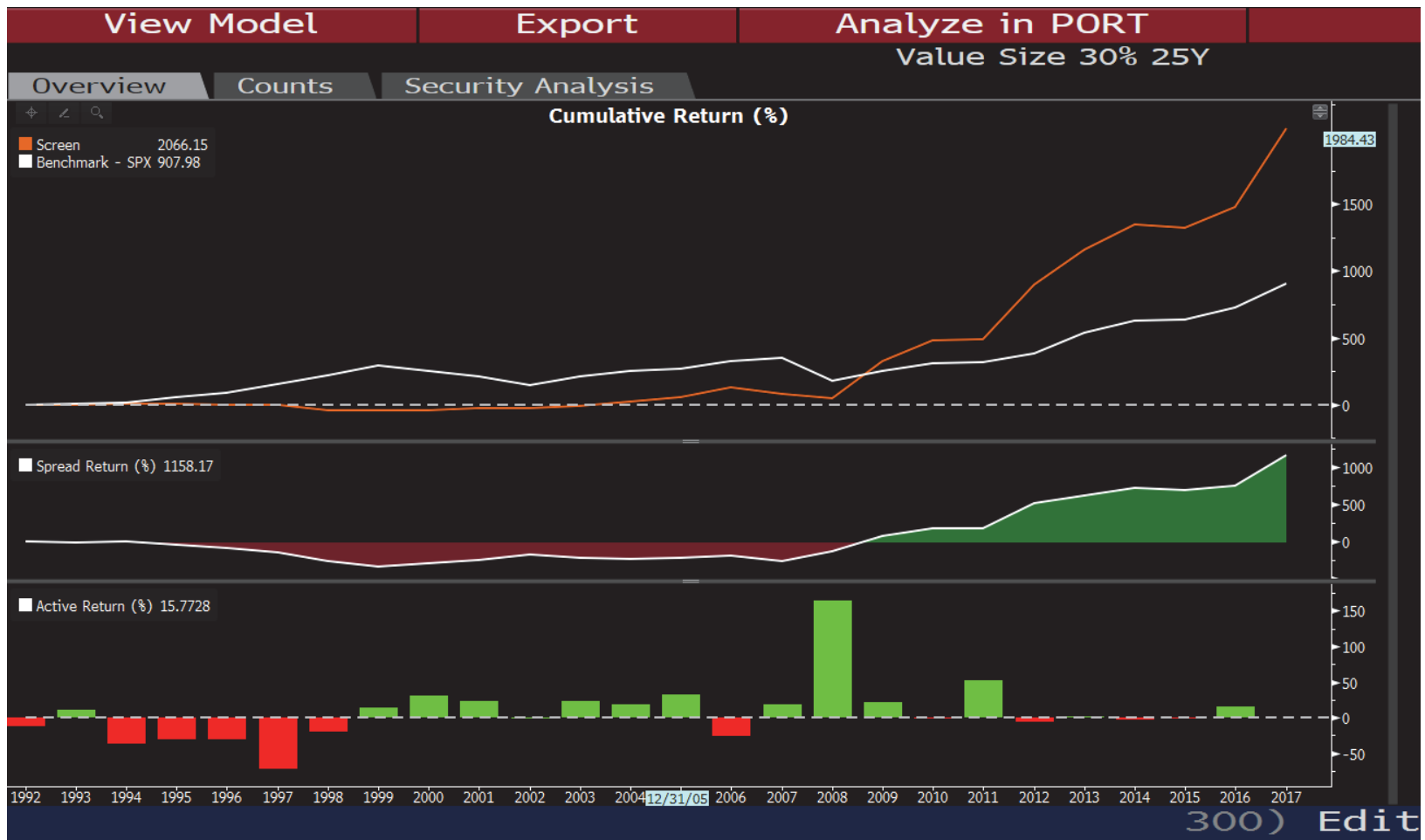




\section{REFERENCES}

Banz, R. W. (1981). The relationship between return and market value of common stocks. Journal of financial economics, 9(1), 3-18.

Bauman, W. S., Conover, C. M., \& Miller, R. E. (1998). Growth versus value and large-cap versus smallcap stocks in international markets. Financial Analysts Journal, 54(2), 75-89.

Chen, N. F., \& Zhang, F. (1998). Risk and return of value stocks. The Journal of Business, 71(4), 501535.

Daniel, K., Grinblatt, M., Titman, S., \& Wermers, R. (1997). Measuring mutual fund performance with characteristic-based benchmarks. The Journal of finance, 52(3), 1035-1058.

De Bondt, W. F., \& Thaler, R. H. (1987). Further evidence on investor overreaction and stock market seasonality. The Journal of Finance, 42(3), 557-581.

Fama, E. F., \& French, K. R. (1998). Value versus growth: The international evidence. The journal of finance, 53(6), 1975-1999.

Haugen, R. A., \& Baker, N. L. (1991). The efficient market inefficiency of capitalization-weighted stock portfolios. The Journal of Portfolio Management, 17(3), 35-40.

Jegadeesh, N., \& Titman, S. (1993). Returns to buying winners and selling losers: Implications for stock market efficiency. The Journal of finance, 48(1), 65-91.

Kahn, R. N., \& Lemmon, M. (2016). The asset manager's dilemma: How smart beta is disrupting the investment management industry. Financial Analysts Journal, 72(1), 15-20.

Lakonishok, J., Shleifer, A., \& Vishny, R. W. (1994). Contrarian investment, extrapolation, and risk. The journal of finance, 49(5), 1541-1578.

Madhogarhia, P. K., \& Lam, M. (2015). Dynamic asset allocation. Journal of Asset Management, 16(5), 293-302.

Madhogarhia, P., Sutton, N. K., \& Kohers, T. (2009). Earnings management practices among growth and value firms. Applied Financial Economics, 19(22), 1767-1778.

Pablo, F., \& Pablo, F. A. (2018). It Has Been Very Easy to Beat the S\&P500 in 2000-2018: Several Examples. SSRN.

Plyakha, Y., Uppal, R., \& Vilkov, G. (2012). Why does an equal-weighted portfolio outperform value-and price-weighted portfolios?

Poterba, J. M., \& Summers, L. H. (1988). Mean reversion in stock prices: Evidence and implications. Journal of financial economics, 22(1), 27-59.

Savor, P. G., \& Gamboa-Cavazos, M. (2011). Holding on to your shorts: When do short sellers retreat?

Skinner, D. J., \& Sloan, R. G. (2002). Earnings surprises, growth expectations, and stock returns or don't let an earnings torpedo sink your portfolio. Review of accounting studies, 7(2-3), 289-312. 